\title{
Change in fraud review proposed
}

A strict definition of fraud and a plan to move the NIH Office of Scientific Integrity out of NiH are a step in the right direction of reforming a system that has not worked well.

FOR more than a decade, the biomedical research enterprise in the United States has struggled, without evident success, to develop fair and efficient procedures for dealing with allegations of scientific fraud. Universities have repeatedly claimed inexperience as an excuse for inadequate investigations, and the three-year-old Office of Scientific Integrity (OSI) at the National Institutes of Health has proved itself uniquely unable to cope. There may be light at the end of the proverbial tunnel.

A senior federal advisory committee has recommended that the government adopt a strict-constructionist definition of fraud and has supported a proposal that OSI be abandoned altogether-good advice on both counts.

One of the main roadblocks in fraud investigations has been the research community's rather astonishing inability to agree on a clear definition (Nature 352, $563 ; 1991)$. As a result those responsible for investigating allegations of wrong doing (including the fraud cops at OSI) have included in their purview not only outright data fabrication but also "practices that seriously deviate from those commonly accepted within the scientific community for proposing, conducting or reporting research'. The trouble here is that there is no consensus about what constitutes commonly accepted practices, thus leaving it to the investigators to decide as they go along whether or not they approve of various laboratory practices.

The tangible consequence of this approach is evident in the case of the OSI $\mathrm{v}$. Robert Gallo at NIH. Gallo who has been cleared of allegations that he "misappropriated' an AIDS virus from French colleagues but he has nonetheless been charged by OSI with not running a tight ship.

The recommendations of the advisory committee, which reports to the Secretary of Health and Human Services (HHS), whose department includes NIH and other major biomedical research agencies, would go a long way to clarifying the issues. First, the committee would define fraud for what it is. Soundly rejecting the view often expressed at academic gatherings that fraud is difficult to define, the committee, chaired by Nicholas Steneck of the University of Michigan, has proposed defining fraud the way the dictionary does. If the Secretary takes the advice (as he should), research fraud would henceforth be defined as 'plagiarism, the fabrication or intentional falsification of data, research procedures or data analysis, or other deliberate misrepresentations in proposing, conducting, reporting or reviewing research'.

It is significant that the committee has adopted this common sense definition that includes intent as an essential element in fraud. In so doing, Steneck and his colleagues have taken a position that runs counter to the current OSI position that intent is irrelevant in determining whether someone is guilty of committing fraud-a position with which NIH director Bernadine Healy also takes strong exception.

Another important recommendation for handling fraud-this one from NIH and HHS staff-while organizational in nature, would bring due process and a sense of faimess and impartiality to the investigatory enterprise. The OSI, now an integral part of the NIH with offices on the NIH campus, would be abolished, to be replaced by a new entity with the ungainly name Office of Research Integrity Assurance (ORIA) that would operate out of the office of the Secretary-along with the Office of the Inspector General, which enforces the department's laws. (It might even be wise to take OSI out of HHS altogether.) Under this scheme, the NIH would be relegated to a role in setting policy (the NIH director would head a new Research Integrity Policy Board)

The Steneck committee also tackled head on numerous complaints that current OSI procedures deny the accused a fair trial. Because OSI staff have taken the position that theirs is a search for scientific truth (rather than for evil-doers), they deny the accused access to the evidence and prohibit the cross-examination of witnesses. Under proposed reforms, the accused would always be entitled to appeal a finding of guilt to an adjudication panel whose activities would most likely be open to public view. They should be, just like the criminal trials they so closely resemble.

The principal argument against moving OSI out of NIH into the more scientifically impersonal reaches of the Secretary's office is that only scientists are qualified to investigate the work of other scientists. It is a valid thought, but the evidence does not bear out an inference that the present system works well. The Gallo case, and the case against Thereza Imanishi-Kari, who is accused of fabricating data in a paper she co-authored with David Baltimore, illustrate the point.

The OSI, understandably lacking the expertise in immunology requisite to an analysis of the Imanishi-Kari paper, is being assisted by a panel of scientific experts, in theory much to the good. However, when two of the three dissented from some of the OSI staff's conclusions in the case (which were leaked to the press), OSI essentially ignored them.

In the Gallo case a panel of researchers from outside the NIH was named not only to provide scientific advice but also to serve as a watchdog, lest the OSI show favouritism toward Gallo as one of NIH's own (it has not). However, NIH to this day has not made plain just what it is the advisory panel, headed by Frederic Richards of Yale, is supposed to do, although it has been in operation for a couple of years. Furthermore, the committee (10 members strong) has itself been accused (whether justly or not) of bias against Gallo.

The OSI's efforts to get independent advice in these prominent cases have fallen short. Perhaps a revamped investigatory office could do better. In any case, a new fraud office, operating with a strict definition of fraud, could escape the illusion that resolving allegations requires establishing scientific truth. In the Imanishi-Kari case, Baltimore has argued that others in the field have produced data that tend to support hers. This is pertinent to a discussion about whether the hypothesis in the paper might be true; it is not relevant to the charge that her data were fabricated.

An additional matter of some importance in investigating fraud is confidentiality. So far, OSI has been unable (or unwilling) to keep its draft reports from finding their way to the press. NIH director Healy has become so distressed about leaks that she has taken the aggressive step of calling in the FBI to determine whether present or former OSI employees are guilty of criminal behaviour (see news story, page 186). The whole business of leaks is another argument in favour of public hearings for scientists who want to appeal the conclusions of the fraud office.

The interminable course of OSI's most public cases, coupled with the growing perception that the system is not fair, are enough to make the case that change is badly needed. In the past, the NIH have seen suggestions to remove OSI as a threat. They should see it as an opportunity to get out of an untenable situation in which the very agency that supports biomedical research also investigates it and, acting as judge and jury, is the arbiter of innocence or guilt.

Barbara J. Culliton 